\title{
A SISTEMÁTICA INCOMPREENSÃO DA TEORIA QUÂNTICA E AS DIFICULDADES DOS PROFESSORES NA INTRODUÇÃO DA FÍSICA MODERNA E CONTEMPORÂNEA NO ENSINO MÉDIO
}

\section{The quantum theory systematic incomprehensibility and teachers difficulties concerning to the introduction of Modern and Contemporary Physics at High School Level}

\author{
Maria Amélia Monteiro ${ }^{1}$ \\ Roberto Nardi ${ }^{2}$ \\ Jenner Barretto Bastos Filho ${ }^{3}$
}

\begin{abstract}
Resumo: O objetivo desta pesquisa é avaliar a proposta de introdução da Física Moderna e Contemporânea no Nível Médio da Educação Básica. Parte-se do pressuposto de que os professores assumem, às vezes até subconscientemente, que a teoria base da FMC é incompreensível. Investigamos, em 2007, os discursos de cinco professores de Física de um município da região Nordeste, visando compreender as possibilidades desses professores introduzirem a FMC em suas aulas de Física e em que medida estas possibilidades estão associadas às suas formações profissionais. Para a construção e análises dos discursos pautamo-nos na Análise de Discurso Francesa e em referenciais da Teoria Crítica da Educação. Constatamos que apesar de atribuírem papel relevante à introdução da FMC no Nível Médio, os professores não estão encarando este desafio.
\end{abstract}

Palavras-chave: Ensino de Física. Ensino da Física Moderna e Contemporânea. Formação de professores de Física. Teoria crítica educacional.

\begin{abstract}
The main goal of this research is to evaluate the proposal to introduce Modern and Contemporary Physics (MCP) in Brazilian secondary and high schools. Our evaluation presupposes that teachers assume sometimes unconsciously, that the MCP basis theory is essentially misunderstood. In 2007, we investigate five in-service Brazilian Northeastern physics teachers discourses, in order to comprehend their perspectives and possibilities to introduce MCP in their classes, as well as, how these possibilities are related to their professional backgrounds. Teachers' discourses were analyzed using as referential the French Discourse Analysis and Critical Educational Theory. We realized that the interviewed teachers, even though attributing relevant role in introducing PMC in that school level, are not facing this challenge.
\end{abstract}

Keywords: Physics teaching. Modern and contemporary physics teaching. Physics teachers education. Critical educational theory.

\footnotetext{
${ }^{1}$ Licenciada em Física, Doutoranda em Educação para a Ciência; Docente, Departamento de Física, Universidade Estadual da Paraíba. Campina Grande, PB, Brasil. amelia@fc.unesp.br

${ }^{2}$ Licenciado em Física, Doutor em Educação; Docente, Departamento de Educação, Programa de Pós-graduação em Educação para a Ciência, Faculdade de Ciências, Unesp, campus de Bauru, SP, Brasil. nardi@ff.unesp.br ${ }^{3}$ Bacharel em Física, Doutor em Física Teórica; Docente, Instituto de Física, Universidade Federal de Alagoas. jenner@fis.ufal.br

${ }^{1}$ End: Juvêncio Arruda, s/n

Bodocongó - Campina Grande, PB

58.109-790 
Monteiro, M. A.; Nardi, R.; Bastos Filhos, J. B.

\section{Introdução}

Uma revisão na literatura específica evidencia um crescente número de pesquisas e iniciativas de elaboração de materiais didáticos visando contribuir com a introdução da Física Moderna e Contemporânea (doravante FMC) na Educação Básica (OSTERMANN e MOREIRA, 2000; GRECA e MOREIRA, 2001). Uma revisão nos anais dos ENPEC também mostra tendência semelhante no contexto brasileiro (MONTEIRO e NARDI, 2007), no qual Terrazzan (1994) é um dos pioneiros.

Várias são as justificativas apontadas por pesquisadores no sentido da FMC ser trabalhada na Educação Básica. Mencionaremos algumas destas, consideradas por nós como exemplares das tendências existentes na literatura.

A partir de uma perspectiva epistemológica, Gil Pérez, Senet e Solbes (1987) defendem que o ensino de tópicos da Física Moderna aos estudantes da Educação Básica poderá contribuir para que os mesmos obtenham uma visão mais coerente de toda a Física, como também da própria natureza do trabalho científico. Os autores acreditam ainda na possibilidade do ensino da mencionada Física contribuir para a superação do ponto de vista de que o desenvolvimento da ciência seja linear e cumulativo.

Stannard (1990) adverte sobre as motivações dos estudantes acerca da FMC. O autor realizou pesquisa com 250 crianças inglesas, com a idade de 12 anos, e constatou que muitas delas já possuíam noções sobre buracos negros e o Big Bang. Constatou também que o interesse em tópicos da FMC, tais como Relatividade, Partículas Elementares, Teoria Quântica, bem como Astrofísica foram os que mais influenciaram estudantes de Física a se interessarem pelo curso.

Em 1986, Aubrecht argumentava que a introdução de tópicos da FMC na Educação Básica possibilitaria que muitos estudantes compreendessem os princípios físicos de artefatos presentes no cotidiano desses, incentivando o interesse pela ciência, o qual muitas vezes tais estudantes trazem para a escola.

A partir da pressuposição de que o conhecimento é uma produção cultural, Torre (1998) apresenta algumas razões para a introdução da FMC na Educação Básica, a saber: a) conectar o estudante com a sua história; b) preservar os estudantes dos obscurantismos pósmodernos; c) possibilitar que o aluno possa localizar corretamente o ser humano na escala temporal e espacial da natureza; d) propiciar o entendimento sobre as múltiplas e evidentes consequências tecnológicas da FMC; e) ensejar beleza, como também prazer, pelo conhecimento, haja vista que tudo isso constitui parte inseparável da cultura, pois o saber nos faz livres e valoriza a humanidade.

Taylor e Zafiratos (1991) sugerem que os princípios básicos da FMC sejam trabalhados nos cursos cujos estudantes não tenham a intenção de optar por profissões científicas. Isso asseguraria que esses conhecimentos fizessem parte do arcabouço cultural de uma maior quantidade de pessoas.

Enfatizando o descompasso entre os conteúdos da física ensinados nas escolas e aqueles que são relevantes para a compreensão de tecnologias presentes no dia-a-dia de muitos estudantes ingleses que frequentam a Educação Básica ou pré-universitária, Shabajee e Postlethwaite (2000) apresentam quatro justificativas para introdução da Física do século XX nos currículos. São elas: 
i) A necessidade de que nos reportemos às pesquisas no campo da cognição e, neste sentido, eles mencionam que crianças têm dificuldades de mudar a sua estrutura cognitiva acerca de questões que foram assimiladas em uma perspectiva limitada. Os autores defendem que a omissão da Física do século XX nos currículos dificultará a aprendizagem subsequente dos estudantes, em relação aos conceitos atinentes à FMC;

ii) A necessidade de levarmos em conta a constatação de que a introdução da Física do século XX nos currículos da educação científica básica poderá dar oportunidade às crianças de desenvolverem um entusiasmo mais duradouro pela ciência;

iii) A necessidade de considerarmos que a Física Moderna poderá ser tratada como um importante elemento cultural. Caso contrário, a relevância da física trabalhada na escola será reduzida;

iv) A necessidade de termos consciência de que a ausência da Física Moderna nos currículos poderá limitar a imaginação pedagógica dos participantes do contexto educacional.

Pautando-se em uma perspectiva mais ampla, Gil Pérez e Solbes (1993) discorrem sobre quatro justificativas em prol da introdução da Física Moderna na Educação Básica. Segundo os autores:

i) Conhecer a sua construção possibilita que o estudante elabore uma visão não-linear da ciência, além de evidenciar que a Física Clássica não explicava alguns problemas emergentes em dada época, o que desencadeou a gênese da Física Moderna;

ii) Possibilitar ao estudante perceber a influência da Física Moderna na sociedade, seja em termos das aplicações tecnológicas, como também pela influência no pensamento e na cultura do seu tempo;

iii) Sintonizar seu estudo com o interesse e a curiosidade que os estudantes desenvolvem por questões mais teóricas;

iv) Possibilitar, ao estudante, compreender melhor a própria Física Clássica, haja vista a possibilidade de mostrar os limites de validade desta, bem como as próprias diferenças entre ambas.

Zanetic (2002) argumenta que a Física deve fazer parte da formação geral do cidadão contemporâneo, independentemente dos interesses individuais ou das motivações profissionais dos mesmos. Por meio de uma argumentação específica, Carvalho e Zanetic (2004) defendem que a introdução da FMC na Educação Básica deverá ocorrer em articulação com a arte. Dentre outras possibilidades, o ensino de Física articulado com várias áreas do conhecimento, favoreceria uma educação "problematizadora" e em sintonia com questões sociais mais amplas (ZANETIC, 2005).

$\mathrm{Na}$ literatura, há recomendações de posturas metodológicas diferenciadas no intuito de se viabilizar a introdução da FMC tanto na Educação Básica, quanto na formação de profissionais. Tais recomendações são classificadas em três grupos:

i) Em uma abordagem metodológica, Helmut Fischler e Michel Lichtfeldt (1993), na Universidade de Berlin, propõem a não utilização de referência aos modelos semiclássicos, como, por exemplo, o átomo de Bohr, ao se inserirem conteúdos da FMC na Educação Básica. Os autores argumentam que referências aos modelos da Física Clássica poderão funcionar como um obstáculo para a aprendizagem conceitual dos tópicos da FMC pelos estudantes.

ii) Outra abordagem metodológica é defendida por Gil Perez e Jordi Solbes (1993), da Universidade de Valência, para os quais a FMC deverá ser apresentada na Educação Básica a 
Monteiro, M. A.; Nardi, R.; Bastos Filhos, J. B.

partir da evolução histórica dos conceitos. Os autores defendem que os limites da Física Clássica sejam debatidos, aclarando, assim, os limites de validade desta. Defendem os autores que a ausência de referências às dificuldades da Física Clássica poderá favorecer o surgimento de erros conceituais por ocasião da interpretação dada pelos estudantes acerca da construção da ciência moderna.

iii) Uma terceira perspectiva metodológica, defendida por Arnold Arons (1990) na Universidade de Washington, EUA, propõe a seleção de alguns tópicos em relação aos quais considerações essenciais devem ser abordadas na Educação Básica. Arons focaliza sua atenção em relação à complexidade matemática subjacente à Teoria da Relatividade. No entanto, o autor defende que se deve buscar sustentação nos tópicos da Física Clássica no ensino dos tópicos da FMC.

Paralelamente aos posicionamentos ou recomendações dos cientistas e pesquisadores, algumas experiências investigando os posicionamentos dos professores vêm sendo realizadas no Brasil. Machado e Nardi (2003), por exemplo, realizaram pesquisa com vinte e quatro professores de Física, dos trinta e nove que trabalham em vinte escolas públicas em um município localizado em estado da região sul do Brasil. Os autores constataram que 50\% dos professores que participaram da pesquisa atribuíram um alto grau de importância à mencionada proposição. Vale salientar que apenas $29 \%$ destes professores frequentemente abordavam alguns tópicos da FMC em suas aulas. Oliveira, Vianna e Gerbassi (2007) pesquisaram as opiniões de dez professores de física atuantes em escolas públicas e particulares, localizadas em um município da região Sudeste do Brasil. Os professores mostraram-se favoráveis à introdução da FMC na Educação Básica, porém, apenas três entre os dez professores haviam introduzido considerações acerca da FMC em seus planejamentos de ensino, reconhecendo que havia sido em uma abordagem esporádica. Solbes, Fernández e González (2001), por sua vez, mencionam que apesar das dificuldades apontadas pela literatura no tocante aos problemas de aprendizagem que persistem em relação à Física Quântica em particular, não se encontram, na literatura, estudos que avaliem o pensamento do professor, tampouco propostas de superação destas dificuldades.

Diante da constatação de que a introdução da FMC no Nível médio, por grupos específicos de professores, não tem ocorrido com a mesma prioridade sugerida pelos pesquisadores, o objetivo central da presente pesquisa é investigar a importância que professores de Física de um município localizado em um estado da região Nordeste do Brasil atribuem à questão. Também investigaremos as perspectivas, possibilidades e dificuldades que os mesmos enfrentam ao tentarem trabalhar a FMC, ou, mesmo, que avaliam que enfrentariam, caso não a tenham ainda trabalhado no Nível médio. Tendo em vista a multiplicidade de tais dificuldades e da inerente complexidade que um tema de tal magnitude enseja, focaremos a nossa pesquisa nos aspectos atinentes à adequação ou não da ortodoxa formação dos professores de Física para atender a contento este propósito, em especial no tocante à teoria quântica. Para isso, conduziremos os nossos propósitos a partir das questões que se seguem: O que os professores consideram como mais relevante para as aulas de física? Qual a importância atribuída por esses professores à introdução da FMC no Ensino Médio? Com quais obstáculos esses professores se deparam para introduzirem a FMC no Ensino Médio, e em que medida essas dificuldades estão relacionadas com suas formações profissionais? 
A sistemática incompreensão da teoria...

\section{Percursos metodológicos da pesquisa}

O corpus da pesquisa foi constituído a partir das interpretações dos discursos de cinco professores, licenciados em Física, que atuam no Nível médio da Educação Básica, em um município da região Nordeste brasileira. Com o intuito de preservar a identidade desses, foram respectivamente nomeados como $\mathrm{P}_{1}, \mathrm{P}_{2}, \mathrm{P}_{3}, \mathrm{P}_{4}$ e $\mathrm{P}_{5}$.

Para a construção do mencionado corpus, os professores participaram de uma entrevista semiestruturada, na qual procuramos focar a visão desses sobre o ensino da FMC, relacionando-a com as respectivas formações. As entrevistas tiveram duração média de cinquenta a noventa minutos, tendo sido as mesmas gravadas em áudio e vídeo e com a prévia permissão dos respectivos professores. As entrevistas foram realizadas no período compreendido entre os meses de maio e setembro de 2007. As questões de pesquisa foram pautadas naquelas mencionadas em nossos objetivos, porém, desdobraram-se em várias outras, muitas vezes tendo, como guia, as respostas apresentadas pelos professores às questões anteriores. Neste sentido, os professores responderam a várias questões distintas.

Salientamos que, apesar do corpus da pesquisa ter sido construído pelos discursos de cinco professores, entrevistamos dez professores de Física. Para a escolha dos cinco dentre os dez entrevistados, nos apoiamos em Gaskel (2003), o qual considera que, quando o aumento da quantidade de entrevistas não traz uma compreensão mais detalhada para as perguntas de pesquisa, então um número menor já é plenamente satisfatório. Deste modo, como as interpretações dos discursos dos demais professores mostram-se recorrentes, então optamos por analisar apenas cinco dos entrevistados.

Para a interpretação dos discursos na presente análise, fizemos recortes nos textos produzidos a partir das entrevistas com os professores e destacamos apenas considerações relacionadas com a importância e as possibilidades de introduzirem ou não a FMC no Nível médio, bem como aspectos presentes na formação desses professores.

As entrevistas foram construídas e interpretadas a partir dos referenciais que se seguem: (a) aqueles próprios da análise de discurso da linha francesa; (b) os que envolvem a formação de professores e o planejamento curricular, no contexto da perspectiva crítica da educação, e; (c) aqueles que são consubstanciados, em uma primeira instância, pelo debate entre os assim chamados fundadores da teoria quântica sobre o caráter compreensível ou não da realidade atômica e, em uma segunda instância, pelas experiências pedagógicas no sentido da inserção da FMC no Nível médio da Educação Básica.

Todos os professores entrevistados possuíam menos de cinco anos de formação na época da realização das entrevistas. O tempo de formação e atuação dos mesmos encontra-se especificado no Quadro 1. 
Monteiro, M. A.; Nardi, R.; Bastos Filhos, J. B.

Quadro 1. Tempo de formação e atuação dos professores entrevistados.

\begin{tabular}{|l|l|}
\hline Professor & \multicolumn{1}{|c|}{ Tempo de formação e atuação } \\
\hline P1 & 2 anos da formação - 1 ano de atuação \\
P2 & 2 anos da formação - 1 ano de atuação \\
P3 & 3 anos da formação -4 anos e seis meses de atuação \\
P4 & 2 anos da formação -3 anos e seis meses de atuação \\
P5 & 3 anos de formação -3 anos e seis meses de atuação \\
\hline
\end{tabular}

A opção por entrevistarmos professores com menos de cinco anos de formação deveu-se ao fato de estes terem concluído sua formação profissional em uma época em que as defesas para a introdução da FMC no Nível médio da Educação Básica já haviam adquirido representatividade na pesquisa em Educação em Ciências. Logo, seria razoável esperar-se que tais pesquisas já tivessem deixado suas marcas nas formações de professores de Física, como também alcançado a Educação Básica.

No quadro abaixo estão dispostas as componentes curriculares relacionadas com a FMC, as quais haviam sido cursadas pelos professores entrevistados, durante a época em que construíam as respectivas formações profissionais.

Quadro 2. Componentes curriculares contemplando a FMC, cursadas pelos professores entrevistados.

\begin{tabular}{|l|l|}
\hline Estrutura da Matéria I & P1; P2; P3; P4; P5 \\
Estrutura da Matéria II & P1; P2 \\
Física Moderna & P1; P2; P3; P4; P5 \\
Mecânica Quântica & P1; P2; P4; P5 \\
\hline
\end{tabular}

Nas duas próximas seções, faremos uma explanação sobre alguns elementos da análise de discurso da escola francesa (AD) e, em seguida, algumas interpretações acerca da teoria quântica, bem como algumas considerações educacionais subjacentes à mesma. Quanto aos referenciais da formação de professores numa perspectiva crítica, que têm sido utilizados como referenciais para construção e interpretação dos discursos, esses serão inseridos no texto à medida que as interpretações estiverem em curso.

\section{A Análise do Discurso: alguns fundamentos}

Na perspectiva da AD, a tarefa do analista do discurso inicia-se tanto pela escolha do corpus - tendo em vista que nesta seleção já estamos investindo em uma perspectiva interpretativa - bem como pelas perguntas que o organizam, orientadas pelo foco da análise. Assim, 
cada tomada do corpus poderá resultar em diferentes interpretações, tendo em vista os distintos objetivos e questões postas pelo analista (ORLANDI, 2002). A autora também menciona que, na construção desse dispositivo de análise, o dito incorpora pressuposições que nem sempre são explicitadas, mas, estão subentendidas. Nesta perspectiva, a autora aponta como necessário revelar-se o contexto de produção do discurso, no sentido de considerar-se o nãodito no lugar do dito.

Acerca da interpretação, Pêcheux (1983) ressalta que todo enunciado é descritível como uma série de pontos de deriva. Estes pontos de deriva, segundo o autor, são aqueles que oferecem lugar à interpretação.

$\mathrm{Na} \mathrm{AD}$, o texto poderá ser considerado como a unidade empírica de análise, a qual materializa ideologias (ORLANDI, 2001). Porém, esta unidade de análise não está associada à sua extensão, podendo ser constituída de uma única letra, um único som, uma única imagem, sinais diacríticos etc. (ORLANDI, 2002). Apoiando-se nas reflexões de Halliday, Orlandi (2004) acrescenta que, para se tornar texto, faz-se necessário ter textualidade, a qual é o resultado da relação do texto consigo mesmo e com a exterioridade. Orlandi acrescenta, ainda, que essas condições da textualidade possibilitam que as palavras adquiram sentido no texto.

Orlandi (2001) também menciona que, na perspectiva da AD, um texto não é uma unidade fechada nela mesma, mas abrem-se diferentes possibilidades de leitura, evidenciando o processo de textualização do discurso, o qual se faz como um jogo da língua. O texto poderá então ser atravessado por vários discursos. Conforme assinala Orlandi (1987, p.159): “[...] o discurso é tomado como conceito teórico e metodológico, e o texto, em contrapartida como conceito analítico correspondente. Há, portanto, uma relação necessária entre eles”.

Orlandi (2001) entende que entre o discurso e o texto existe um espaço de limites fluídos e o ajuste entre os mesmos resulta em uma multiplicidade de sentidos, abrindo espaço para o simbólico. Alerta também que o discurso não é um conjunto de textos, mas um objeto construído pela análise. Logo, o discurso é uma prática (ORLANDI, 2006). Essa noção é uma influência de Michel Foucault (2005), para quem a prática discursiva não está separada de outras práticas, como, por exemplo, da prática social.

As palavras incorporam as marcas das posições de quem as produz e de quem as interpreta, as quais são colocadas em jogo no processo sócio-histórico em que se constituem (PÊCHEUX, 1983). Com isso, pode-se assegurar que o discurso materializa ideologias. Ainda na perspectiva da $\mathrm{AD}$, o sentido da palavra não existe em si mesmo, mas é adquirido a partir das condições de produção. Esta consiste basicamente no sujeito e no lugar ocupado por este. Tal perspectiva encontra eco em Bakhtin (2006), tendo em vista o fato de considerar que se enuncia para alguém a partir de um determinado lugar, ou de uma posição sócio-histórica. Além disso, o outro também ocupa uma determinada posição, sendo estes lugares constitutivos da enunciação. Por isso, a enunciação, para Bakhtin, não é um ato individual, mas um ato eminentemente social.

Vale salientar que o lugar ocupado pelo sujeito no discurso não compreende apenas a realidade física ou institucional que o mesmo ocupa. Pertencem também, ao mesmo, as representações imaginárias que os participantes do discurso fazem da sua identidade, bem como os referentes do discurso. As posições-imaginárias são constituídas pelos já ditos por outras vozes esquecidas, mas que participam do jogo discursivo. Com isso, pode-se inferir que o discurso realiza-se no sujeito, porém, não se origina no mesmo. 
Monteiro, M. A.; Nardi, R.; Bastos Filhos, J. B.

Discurso não é sinônimo de mensagem, haja vista que o silêncio, semelhantemente à palavra, também é discurso. Nesta perspectiva, Pêcheux (2006) ressalta que discurso é efeito de sentido entre interlocutores. Assim, o silêncio também faz parte da investigação do analista, no sentido de o mesmo ter significado. Orlandi (1995) menciona a existência de várias formas de silêncio, dentre elas, o silêncio proposto, e o silêncio imposto. O silêncio proposto representa uma forma de resistência ou de autoproteção. O silêncio imposto, por sua vez, está vinculado a uma exclusão, sendo esta uma forma de dominação.

A relação do discurso com a memória discursiva é entendida por Orlandi (2002) como interdiscurso. A partir desta memória, o discurso vincula-se também a quem é endereçado, logo, fazendo eco nesta assertiva o dialogismo bakhtiniano. É aquilo que foi falado por outra pessoa, em outra época, em outro lugar, já pertencendo ao anonimato, porém, fazendo presença naquilo que está sendo dito e afetado pela significação dada pelo sujeito em uma situação discursiva. Esse dito tem história, tem filiação, o qual é entendido como produções de sentido, que constituem as condições de produção dos discursos. São outras vozes das quais não se sabe ao certo a origem, mas as mesmas não pedem licença para se fazerem presentes nos discursos.

Outro fator relacionado com as condições de produção que constituem as estratégias discursivas é o "mecanismo de antecipação". Neste o locutor tenta colocar-se no local daquele que ouve as palavras e regula a argumentação de tal forma que optará pelo modo que produz ou pensa produzir o efeito desejado no interlocutor (ORLANDI, 2006).

O terceiro fator relacionado com as condições de producão que constituem os discursos é denominado "relações de forças". Nesta noção, o lugar do qual o sujeito fala constitui o que ele diz. Reportando-se às relações de força que permeiam o contexto educacional, Orlandi (2002, p. 39) assinala: "Assim, se o sujeito fala a partir do lugar de professor, suas palavras significam de modo diferente do que se falasse do lugar do aluno".

\section{Duas concepções diferentes para o ensino de mecânica quântica}

No que concerne ao ensino da mecânica quântica, nos anos sessenta do século XX, Richard Phillips Feynman, Robert Leighton e Matthew Sands (FEYNMAN, LEIGHTON e SANDS, 1965) propuseram uma experiência pedagógica importantíssima, muita criativa e singular, que consistiu numa nova organização dos conteúdos, o que, no fundo, implicava uma nova ênfase dada aos conceitos abordados. Essa experiência era claramente contrastante com a maneira habitual de se ensinar a mecânica quântica no Ensino Superior. Essa nova organização dos conteúdos era tal que elegia o conceito de amplitude de probabilidade como central, e que, portanto, este deveria ser introduzido e trabalhado já a partir do início do curso, diferentemente do padrão habitual que consistia na resolução da equação de Schrödinger para exemplares emblemáticos da teoria quântica (partícula livre, átomo de Hidrogênio, oscilador harmônico, partícula sujeita a um campo magnético constante etc.). Feynman, Leighton e Sands remeteram a equação de Schrödinger para o último capítulo (21), discutindo-a em conexão com o contexto clássico, assunto que foi matéria de um de seus seminários sobre a supercondutividade.

Um dos objetivos precípuos de Feynman, Leighton e Sands, que podemos considerar como sendo um novo Programa Pedagógico de Ensino (PPE) para a mecânica quântica, era o de apresentar os conceitos quânticos de uma maneira descolada dos conceitos clássicos. A fim 
A sistemática incompreensão da teoria...

de analisar este Programa, vejamos o que eles escreveram no primeiro parágrafo do capítulo 5 do livro Quantum Mechanics:

In this chapter we really begin the quantum mechanics proper - in the sense that we are going to describe a quantum mechanical phenomenon in a completely quantum mechanical way. We will make no apologies and no attempt to find connections to classical mechanics. We want to talk about something new in a new language. (FEYNMAN, LEIGHTON e SANDS, 1965, p. 1)

O fato de os autores declararem que não vão pedir desculpas por não articularem qualquer conexão com a física clássica, aliado ao fato de declararem que querem apresentar a mecânica quântica como algo novo e numa nova linguagem, revela que o PPE desses autores considera que a tradição pregressa, constituída pela mecânica clássica, não é essencial para a compreensão dos novos conceitos quânticos.

Vejamos, agora, um texto de Bohr. Ele escreveu:

I advocated a point of view conveniently termed "complementarity", suited to embrace the characteristics features of individuality of quantum phenomena, and at the same time to clarify the peculiar aspects of observational problem in the field of experience. For this purpose, it is decisive to recognize that, however far the phenomena transcend the scope of classical physics explanation, the account of all evidence must be expressed in classical terms. (BOHR, 1961, p. 39)

Do confronto direto entre as duas citações acima, emerge uma situação contraditória, pois os três autores primeiramente referidos (Feynman, Leighton e Sands) se propõem a iniciar um curso de mecânica quântica no qual os termos clássicos são programaticamente evitados ou esquecidos. $\mathrm{Na}$ outra citação, Bohr defende a tese segundo a qual, em que pese o fato de os fenômenos quânticos transcenderem o escopo da física clássica, esses devem ser (must be) expressos em termos clássicos.

A flagrante contradição entre esses autores manifesta-se claramente no fato de que, enquanto os primeiros alegam ser possível expressar os fenômenos quânticos como algo novo em uma nova linguagem, Bohr assevera que isso não é possível, na medida em que esses fenômenos devem ser expressos em termos clássicos. Logo, as duas perspectivas não podem ser conciliadas.

Essa contradição se reforça ainda mais se nos lembrarmos que Feynman considera-se ligado à corrente dominante, que é a interpretação de Copenhague da Mecânica Quântica, cujo principal autor é Bohr, fato este que se depreende como evidente da leitura de seu livro.

No que concerne a Bohr, não se trata, portanto, de uma nova linguagem expressando algo novo, e sim de algo realmente novo, que é expresso em termos clássicos, tendo em vista a introdução ad hoc do Princípio da Mútua Exclusão que é a essência do Princípio da Complementaridade de Bohr. Em palavras breves, os termos clássicos são imprescindíveis na descrição desses fenômenos microscópicos, em que pese esses termos clássicos devam ser, segundo Bohr, mutuamente excluidos. 
Monteiro, M. A.; Nardi, R.; Bastos Filhos, J. B.

Inferimos, assim, tanto do confronto direto dos textos, quanto das entrelinhas ensejadas por esses; e que, a despeito de Feynman ter sido considerado um físico importante, e que sabia muito bem a sua disciplina, ele não comunga, nesse aspecto, com o pensamento de Bohr. Em outras palavras, apesar de Feynman se considerar como alguém engajado nas linhas da Interpretação de Copenhague, ele não interpreta a contento importantes aspectos da própria Interpretação de Copenhague na sua principal versão, que é a de Bohr.

Se Feynman e muitos outros bons autores caíram nessa armadilha, o que não diríamos das sucessivas gerações de pesquisadores e professores que interpretam essas ideias que, na verdade, constituem um grande pântano conceitual?

Na nossa construção, também podemos inferir discursos idiossincráticos dos professores de física que são ecos desse pântano conceitual. Em outras palavras, esses discursos fazem emergir a ideia de uma eventual incompreensibilidade da realidade microscópica, que somente é amenizada pelo sucesso retumbante de um formalismo matemático rigoroso que, infelizmente, por ser pouco intuitivo, funciona como algo que se distancia do mundo habitual das intuições espaço-temporais propiciadas pela teoria clássica. Para uma análise circunstanciada, ver Bastos Filho (1994, 2001, e 2004).

\section{Algumas interpretações dos discursos dos professores acerca do ensino da física moderna e contemporânea}

Os questionamentos iniciais dirigidos aos professores que participaram das entrevistas se processaram de uma maneira tal que inicialmente viéssemos a identificar a importância conferida por eles quanto àquilo que deveria ser abordado nas suas aulas. Também visávamos identificar tanto os seus anseios e o que deles se requeria, quanto conhecer os obstáculos que os impediam de cumprir o mister de introduzirem a FMC no Ensino Médio, em função de suas lacunas de formação.

O professor $\mathrm{P}_{1}$ mencionou que gostaria de trabalhar com atividades práticas, elaboradas com materiais de baixo custo, tendo em vista que, se devidamente planejadas, suplantarse-ia grande parte das dificuldades de aprendizagem dos estudantes. O professor $\mathrm{P}_{4}$ também mencionou a ausência de condições para realizar atividades experimentais nas aulas de Física como uma problemática no ambiente escolar. Mencionou que, com a realização de atividades experimentais, os estudantes certamente mostrar-se-iam bastante motivados nas aulas de física. Apesar do entusiasmo dos professores $\mathrm{P}_{1}$ e $\mathrm{P}_{4}$ em relação às atividades experimentais, esses mencionaram não terem tido uma preparação minimamente satisfatória durante suas formações profissionais no tocante ao planejamento e ao uso dos experimentos didáticos.

$\mathrm{O}$ professor $\mathrm{P}_{2}$ argumentou em torno da sua dificuldade em relacionar a física com as experiências dos estudantes. Alegou que, durante a sua formação profissional, menções acerca da importância dessa abordagem foram bastante recorrentes nas disciplinas, por ele denominadas "disciplinas pedagógicas". Porém, apesar das recorrentes menções, alega não ter tido a devida fundamentação teórica. O professor $\mathrm{P}_{2}$ também reconheceu a importância dessa abordagem, ao admitir que, no contexto das salas de aulas, há uma homogeneidade de experiências. Mas, devido à situação econômica limite em que vive a maioria dos estudantes das escolas públicas, ele reconhece não possuir convicção de que esses estudantes possam se interessar pela aprendizagem de algo, independentemente da abordagem desenvolvida pelo professor. 
O professor $\mathrm{P}_{5}$ também ressaltou como importante relacionar a Física com as experiências dos estudantes, apesar de não fazê-lo, costumeiramente. No entanto, apontou as programações restritas e lineares dos livros didáticos como o maior impedimento para a mencionada abordagem. Questionado pela elaboração de um planejamento que não se pautasse na sequência do livro didático, alegou que tal proposição propiciaria conflitos nos estudantes, já condicionados a seguirem a sequência dos livros. Tais conflitos, certamente, causariam inquietações mais amplas no contexto escolar, alegou o professor $\mathrm{P}_{5}$. Também mencionou que, certamente, teria muitas dificuldades em relacionar a Física com as experiências dos estudantes, haja vista que, na formação dele, esta perspectiva de abordagem não foi contemplada.

Para o professor $\mathrm{P}_{3}$, a sua formação profissional como um todo foi bastante deficiente, tendo em vista que a maioria das abordagens de ensino conduzidas pelos docentes do Departamento de Física se restringia meramente à repetição dos livros didáticos adotados. Em relação às abordagens de ensino dos docentes do Departamento de Educação, o professor $\mathrm{P}_{3}$ alegou que os mesmos não procediam com um aprofundamento teórico adequado, até porque tais professores desconhecem a Física. Argumentou ele que os professores do Departamento de Educação, por desconhecerem a Física, não poderiam dar exemplos representativos que significassem uma contextualização genuinamente interdisciplinar das suas recomendações metodológicas. Reportando-se a este contexto, declara:

'Dižem que é importante a interdisciplinaridade, que é importante associar os conteúdos aos conhecimentos do aluno, essas coisas [...] Só que, ficam apenas no discurso. [...] Não aprofundam, não fazem conexão com a Física, com os conceitos da Física”. ( $\left.\mathrm{P}_{3}\right)$

Ao falarem espontaneamente acerca das principais lacunas em suas formações, bem como das implicações destas nas respectivas atuações nas salas de aulas, o ensino da FMC não se mostrou na memória de nenhum dos professores. Além disso, constatamos que os professores entrevistados nunca haviam introduzido a FMC em seus planejamentos de ensino, como também desconheciam quem o fizesse entre os seus pares. Considerando que, na $\mathrm{AD}$, o silêncio também é discurso e o mesmo faz parte da análise (PÊCHEUX, 2006), investiguemos o silêncio dos professores em relação à introdução da FMC em seus planejamentos de ensino, com o intuito de aclararmos se este é um silêncio proposto, e/ou imposto aos professores, pelos respectivos integrantes do contexto educacional, conforme discute Orlandi (1995).

A ausência da FMC nos planejamentos de ensino dos professores entrevistados, bem como dos seus pares, evidencia um descompasso entre as intenções dos professores de Física do nível médio e as proposições dos pesquisadores, em termos de abordagens para a educação científica, a exemplo de Gil Pérez, Senet e Solbes (1987), Stannard (1990), Torre (1998) e outros. A despeito desta constatação, bem como do lugar e posição ocupados pelos sujeitos, haja vista que a mesma interfere na produção dos sentidos, fazemos os seguintes questionamentos: De que lugares e com que sentidos falam esses pesquisadores acerca da importância da FMC na Educação Básica? Para quem e com que intenções falam os mesmos, tendo em vista que os seus propósitos e sugestões acerca do ensino da FMC não parecem ter deixado suas marcas nos discursos dos professores entrevistados?

O descompasso entre as sugestões dos pesquisadores acerca do ensino da FMC e as intenções dos professores de Física, aqui entrevistados, assemelha-se às constatações de Al- 
Monteiro, M. A.; Nardi, R.; Bastos Filhos, J. B.

meida (2003) acerca da leitura das recomendações da academia, endereçada ao professor de física da Educação Básica brasileira. A autora assinala:

Freqüentemente tem sido dito ao professor o que fazer, sem associação com as condições em que pode ser feito, e, principalmente, sem a origem e possíveis determinantes das recomendações que lhe são dirigidas. E, além disso, algumas vezes, os próprios produtores e difusores desse ideário não se questionam sobre seus princípios e significação. (ALMEIDA, 2003, p. 5)

Tendo em vista que, na AD, silêncio também é discurso (ORLANDI, 1995), então buscamos aclarar se o silêncio dos professores em relação à introdução da FMC no Nível médio estaria associado às convicções dos mesmos, ou se estaria associado às lacunas nas suas respectivas formações, ou, ainda, se estaria associado a outras motivações. No sentido de aclarar tais questionamentos, focamos nosso diálogo com os professores.

Quando explicitamente questionados acerca do ensino da FMC no Nível médio, todos os professores declararam a relevância de tal proposição. Leiamos algumas justificativas nas falas dos mesmos.

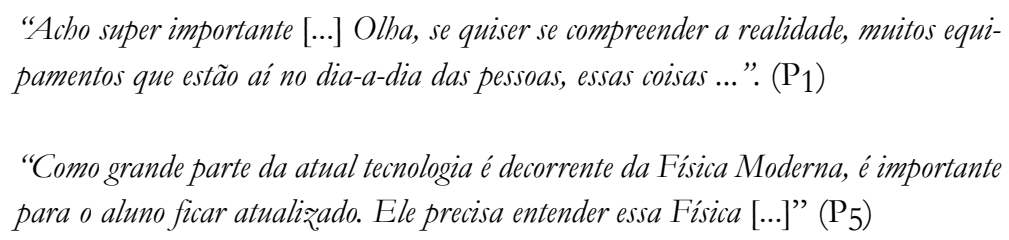

Percebe-se que, para os professores P1 e P5, a principal importância da FMC no Nível médio restringe-se à possibilidade de os estudantes compreenderem as tecnologias presentes em seu entorno, alegando serem as mesmas decorrentes de aplicações tecnológicas da FMC. Interpretamos, assim, que se configura um discurso que incorpora uma visão reducionista e utilitarista acerca da FMC, com propósitos em sintonia com a razão instrumental - ou seja, a organização dos meios com o intuito de atingirem-se determinadas finalidades. Essa concepção de razão, prevalecente na sociedade industrial moderna, recebeu críticas contundentes dos teóricos da Escola de Frankfurt, alegando que a mesma prestava-se como um instrumento de dominação. A razão instrumental havia suplantado as proposições de emancipação, propaladas pela racionalidade humanística do Iluminismo (ADORNO e HORKHEIMER, 1985).

Opondo-se à razão instrumental, baseada no paradigma cartesiano-newtoniano, porém, ainda valorizando o potencial emancipador da razão, Habermas (2006) propõe a razão comunicativa. Esta não se fundamenta na filosofia da consciência, mas, na filosofia da linguagem. Por isso, argumenta que os sujeitos poderão chegar a um entendimento edificante por meio da fala argumentativa, resultando, assim, na emancipação ativa dos mesmos. Para a racionalidade comunicativa é imprescindível que os sujeitos façam acordos sem coações. Na perspectiva habermasiana, a ciência tecnicizada não deverá ser compreendida apenas como uma força produtiva neutra, tendo em vista que esconde um projeto de sociedade determinado por interesses contrários à emancipação humana (HABERMANS, 1987). A partir desta perspecti- 
va, Habermas busca restabelecer a articulação entre saber teórico e ação humana, com o intuito de encontrar o nexo entre a prática social - a qual considera como imanente ao mundo da vida - e o saber científico - fruto da racionalidade instrumental. Tal proposição certamente romperá com a postura reducionista-positivista que separa teoria e prática.

Tal como nas falas dos professores $\mathrm{P}_{1}$ e $\mathrm{P}_{5}$, a importância da FMC na Educação Básica dos estudantes também se manifesta de maneira recorrente na fala do professor $\mathrm{P}_{2}$; a importância da FMC na Educação Básica para os estudantes é novamente reiterada; argumenta o professor $\mathrm{P}_{2}$ em prol da necessidade de os alunos compreenderem as tecnologias em seu entorno.

'Eu acredito que é relevante. Prá mim, é altamente relevante. Até para os alunos terem consciência de que a física não parou. É ... teve grandes contribuições da física do século XX, é [...]. E o que temos hoje como tecnologia, justamente que advém dessa física, com relação a alguns equipamentos [...] Esse tipo de coisa, prá mostrar que a coisa não é só estudar dentro do laboratório, dentro das universidades [...]". ( $\left.\mathrm{P}_{2}\right)$

A relevância que os professores $\mathrm{P}_{1}, \mathrm{P}_{2}$ e $\mathrm{P}_{5}$ atribuem à $\mathrm{FMC}$ na educação básica para possibilitar aos estudantes compreenderem as tecnologias em seu entorno, denotam as marcas de vozes presentes nos $\mathrm{PCN}+$, à medida que apresenta propósitos bastante restritos para o ensino da FMC.

Alguns aspectos da chamada Física Moderna serão indispensáveis para permitir aos jovens adquirir uma compreensão mais abrangente sobre como se constitui a matéria, de forma que tenham contato com diferentes e novos materiais, cristais líquidos e laser presentes nos utensílios tecnológicos, ou com o desenvolvimento da eletrônica, dos circuitos integrados e dos microprocessadores. (BRASIL, 2002, p. 70)

Acerca da sintonia das recomendações para o ensino da FMC contidas nos PCN+ com os propósitos dos professores de Física, interpretamos que essas recomendações emergem como vozes sem origem explicitada, porém estão fazendo sentido nas vozes dos professores, conforme mencionado por Orlandi (2002).

Não identificamos, nas falas dos professores $\mathrm{P}_{1}, \mathrm{P}_{2}$ e $\mathrm{P}_{5}$, perspectivas e possibilidades de introduzirem a FMC no nível médio com o intuito de, a partir do diálogo com os estudantes, discutirem a ciência e a tecnologia como expressão dos interesses e criatividade humanos. $\mathrm{Ou}$ mesmo outras abordagens, conforme sugerem Taylor e Zafiratos (1991), Carvalho e Zanetic (2004), por exemplo. Tampouco identificamos, nas intenções dos professores, perspectivas e possibilidades para, por meio do ensino da FMC, desencadearem a problematização acerca dos propósitos e implicações das tecnologias elaboradas a partir da mencionada Física.

Estamos aqui adotando a "problematização" no sentido freireano, a qual ocorre mediante uma ação dialógica entre os sujeitos e possibilita provocar questionamentos, desafiar a compreensão e a argumentação dos participantes. Nessa perspectiva, a relação dialética entre ação e reflexão, o $e$ de um, não anula o outro, mas transforma-o. Logo, trata-se de uma educação científica que tem como meta a emancipação humana. Em sintonia com esta perspectiva, 
Monteiro, M. A.; Nardi, R.; Bastos Filhos, J. B.

Freire (1993, P. 78) assinala: "existir humanamente, é pronunciar o mundo, é modificá-lo. O mundo pronunciado, por sua vez, se volta problematizado aos sujeitos pronunciantes, a exigir deles novo pronunciar."

O professor $\mathrm{P}_{3}$ menciona que é importante o ensino da FMC, assim como o da Física Clássica, mas, tal importância está relacionada à abordagem com a qual se trabalha a mesma com os estudantes.

"[...] o conteúdo por si só, não traz nenbuma inovação. Precisaria de outras abordagens. [...] Acho que toda a Física é importante, depende da discussão que o professor consegue fazer". ( $\left.\mathrm{P}_{3}\right)$

Percebe-se que, para o professor $\mathrm{P}_{3}$, a importância do ensino da FMC incorpora preocupações mais amplas que a simples aprendizagem dos conceitos pelos estudantes. À medida que a importância de toda a Física no contexto educacional está associada à discussão feita pelo professor com os integrantes do contexto, o porquê de ensinar é prevalecente em relação ao como ensinar. Nesta perspectiva, percebe-se, no discurso do professor $\mathrm{P}_{3}$, as marcas de uma concepção curricular pautada na teoria crítica, para a qual é perspectiva fundante o conhecimento além do âmbito cognitivo e técnico (SILVA, 2004).

Para o professor P4, a FMC é importante por se tratar de um conhecimento produzido recentemente e decorrente do desenvolvimento da Física Clássica. Com isso, não demonstra perceber uma ruptura de pressupostos entre as duas abordagens da Física.

"Pra o aluno saber que aquele conhecimento da Física Clássica não parou nela mesma. Continuou e evidenciou seus limites. A mente precisa estar aberta para outras possibilidades decorrentes da evolução da Física Moderna e não se limitar apenas aos conhecimentos da Física Clássica”. ( $\left.\mathrm{P}_{4}\right)$.

Tendo em vista que os professores entrevistados atribuíram relevância ao ensino da FMC no Nível médio da Educação Básica, semelhantemente aos professores pesquisados por Machado e Nardi (2003) e Oliveira, Vianna e Gerbassi (2007), quais os motivos que os impedem de fazê-lo? Seriam restrições existentes no contexto escolar? Ou seriam lacunas nas respectivas formações?

Os professores $\mathrm{P}_{1}$ e $\mathrm{P}_{5}$, por exemplo, alegaram que o reduzido tempo disponibilizado semanalmente às aulas, associado a uma extensiva quantidade de conceitos da Física Clássica a serem trabalhados, eram as motivações a não introduzirem a FMC em seus planejamentos de ensino.

"Primeiro. Temos muitos conteúdos e pouco tempo. Não vejo como. Não vejo como fazer isso. Normalmente a gente sabe que começa com a mecanica, mas onde vai terminar, o que vai avançar, é imprevisivel. Às vezes a gente chega no terceiro ano e não conclui a parte de mecânica. Além da programação em si, existem aquelas turmas que não tiveram professor de física. São muitas coisas". ( $\left.\mathrm{P}_{1}\right)$ 
A sistemática incompreensão da teoria...

"O tempo não é suficiente nem prá trabalhar a Física Clássica da programação. A Física Moderna nem pensar. São apenas duas aulas por semana e com as dificuldades dos alunos, a gente não consegue avançar muito. Assim não dá pra terminar a Física Clássica”. ( $\left.\mathrm{P}_{5}\right)$

Os professores $\mathrm{P}_{1}$ e $\mathrm{P}_{5}$ foram solicitados a idealizar situações nas quais as restrições temporais para as aulas de Física fossem suplantadas. Em outras palavras, qual seria o momento propício para idealizá-las e quais as estratégias e abordagens que utilizariam para introduzirem a FMC em suas aulas.

"Com certeza, depois de todos os conteúdos do volume três. Ai eu ia trabalhar na seqüência o volume um, volume dois e depois do volume três. Com isso, já no último ano, o aluno ia ter base para que a Física Moderna fosse trabalhada". (P1)

"Física Moderna seria a parte final da programação. Na parte final da programação do terceiro ano. Depois que trabalhasse a mecânica, a termodinâmica, ondas, quem sabe ótica, a eletricidade que no terceiro ano. Assim, quando terminasse toda a programação da Física Clássica, aí começava com a Física Moderna”. (P5)

A proposição dos professores $\mathrm{P}_{1}$ e $\mathrm{P}_{5}$ em introduzir a FMC no último ano do Ensino Médio, após abordar toda a Física Clássica, seguindo uma sequência temporal da construção da ciência, incorpora vozes semelhantes às prevalecentes em uma linha de produção fabril. Segundo Silva (2004) esse perfil de estruturação curricular configurou-se a partir da segunda década do século XX, nos Estados Unidos da América, porém com influências em diversos países. A mesma foi inspirada na administração científica proposta por Taylor aos processos fabris. Com tal modelo de proposição curricular, visavam eles ajustar a escola aos feitos da racionalidade e da eficiência requeridos por uma sociedade que enfrentava um crescente processo de industrialização e de urbanização (SILVA e MOREIRA, 1994).

Acerca das possíveis estratégias a serem utilizadas com o intuito de introduzir a FMC no Nível médio, o professor $\mathrm{P}_{1}$ mostra-se reticente.

"Olha. Não tenho como dizer agora. Precisaria de um tempo pra pensar. [...] Olha. Como falei. Não tenho como dizer agora. Realmente preciso de um tempo. De um tempo prá pensar em tudo isso. Não vejo como trabalhar aquele formalismo matemático no Ensino Médio. Eu não tenho uma resposta prá essa situação, porque é muito nova prá mim. É totalmente nova [...] Os alunos não compreendem o formalismo matemático. Não vejo como trabalhar aquele formalismo matemático no Ensino Médio". ( $\left.\mathrm{P}_{1}\right)$.

Evidencia-se, na fala do professor $\mathrm{P}_{1}$, uma compreensão da FMC restrita ao formalismo matemático da mesma, o qual inviabilizaria a sua introdução no Ensino Médio. Tal perspectiva inviabiliza também a possibilidade de a FMC contribuir para uma educação científica crítica e emancipatória, como também de ser abordada em articulação com a cultura, conforme sugerem Torre (1998), Carvalho e Zanetic (2004) e outros. 
Monteiro, M. A.; Nardi, R.; Bastos Filhos, J. B.

Os professores $\mathrm{P}_{4}$ e $\mathrm{P}_{5}$ também se mostram reticentes em relação à introdução da FMC nas aulas de Física, no entanto, remetem à ausência de experiências em relação a tal propósito. Semelhantemente ao professor $\mathrm{P}_{1}$, não evidenciam nenhuma teorização acerca da mencionada possibilidade.

"Não tenho experiência nenhuma com a Física Moderna e Contemporânea nas aulas de Física. Nas minhas aulas, aqui na escola. Como eu não tenho experiência com essa situação, eu preciso, é, eu teria que ter um tempo pra analisar, saber o que é possivel fazer. Mas, é muito difícil. Eu acho”. ( $\left.\mathrm{P}_{4}\right)$

Como ainda não trabalhei a Física Moderna e Contemporânea no ensino médio, prefiro não opinar no momento. Também não tive a Física Moderna nas aulas de Física quando eu estudava o Ensino Médio. Assim, preciso de conhecer alguma experiência”. ( $\left.\mathrm{P}_{5}\right)$

Os professores $\mathrm{P}_{2}, \mathrm{P}_{3}$ e $\mathrm{P}_{4}$ apontam lacunas em sua formação no tocante à introdução da FMC no Ensino Médio. Acerca destas dificuldades, assinalam:

"Como falei, não sei se existem técnicas mais atuais, dentro da área de educação, dentro dessa área pedagógica, mostrando como ela pode ser trabalhada essa parte de Física Moderna, como ela pode ser exposta, como ela pode ser contextualizada, como pode ser abordada em sala de aula. Realmente eu desconbeço. Talvez até exista”. ( $\left.\mathrm{P}_{2}\right)$

"Com as aulas que tive, fica difícil até me situar. Pelo menos agora, nesse momento, não sei como fazer isso. Preciso até analisar os livros, o que eles abordam, como eles abordam. Não dá prá ensinar tudo aquilo que aprendi, tudo aquilo que foi trabalhado na programação quando cursei as disciplinas durante o curso". ( $\left.\mathrm{P}_{3}\right)$

"Falar agora? Simplesmente não sei. Preciso me situar em relação a isso. Como está sendo feito? O que é abordado? São questões que eu teria que conhecer. Saber como outras pessoas têm feito isso com seus alunos do Ensino Médio, porque no momento eu não sei”. (P4)

No discurso do professor $\mathrm{P}_{2}$ perpassa a concepção de estratégias de ensino como uma técnica - "técnica atual ou adequada". Além disso, a implementação das "técnicas de ensino" restringir-se-ia à "área de educação" e à "área pedagógica". Em oposição à perspectiva de que os professores sejam formados como sendo técnicos, Silva (2004, p. 54-55) assinala: “[...] os professores e as professoras não podem ser vistos como técnicos e burocratas, mas como pessoas envolvidas nas atividades da crítica e do questionamento, a serviço do processo de emancipação e libertação".

Atribuir à área pedagógica e à área de educação o papel de apresentar técnicas de exposição da FMC para estudantes da educação básica, conforme identificado no discurso do professor P2, perpassa uma voz sem nome, conforme pontuado por Orlandi (2002), a qual traz as marcas de uma matriz curricular estruturada em disciplinas de conteúdos específicos e disciplinas 
A sistemática incompreensão da teoria...

pedagógicas, sendo os mesmos desenvolvidos com abordagens e propósitos distintos. Segundo Pereira (2000) este modelo foi seguido pela maioria dos cursos de licenciatura no Brasil, recebendo a denominação de modelo " $3+1$ ". Nos três primeiros anos do curso, predominavam as disciplinas de conteúdos específicos e, no último ano, as disciplinas de natureza pedagógica. $\mathrm{O}$ autor menciona ainda que se trata de uma herança advinda do curso de pedagogia.

$\mathrm{O}$ professor $\mathrm{P}_{3}$ discorre sobre características da sua formação em relação à $\mathrm{FMC}$, a qual, segundo ele, foi excessivamente pautada em um formalismo matemático. Mostra-se reticente em relação à introdução da FMC nas aulas do Ensino Médio. Menciona que é uma física que requer um pouco mais de abstração, porém, ao contrário da Física Clássica, a qual, quando o professor que possui um domínio suficiente da mesma poderá apenas fazer um resumo dos conceitos dos livros didáticos utilizados na formação dele. Com a FMC, acredita ele que essa estratégia seja inválida. Reportando-se a um tópico específico, exemplifica:

"É se retirarmos os cálculos da Física Quântica. Apenas um exemplo. Pronto, usamos um livro de Mecânica Quântica. Por exemplo, naquele capitulo que fala da equação de Schroedinger. É, você usa a EDP, a EDO, encontra aquelas constantes. Se tirar os cálculos, o que fica? Nada. São os números quânticos. Se retirar os cálculos, o que fica? Nada! Acho que precisa entender como aquilo surgiu, a sua história". ( $\left.\mathrm{P}_{3}\right)$

Percebe-se, nos discursos dos professores, que durante as respectivas formações foram contemplados, direta ou indiretamente, com abordagens da Mecânica Quântica que trazem as marcas do Programa Pedagógico de Feynman, Leighton e Sands (1965). A adoção deste formalismo parece não ter contribuído para que os mencionados professores tenham construído uma visão conceitual, epistemológica e ontológica satisfatória da mencionada física, resultando na impossibilidade de eles fazerem as adequações pertinentes e introduzirem a FMC no nível médio da Educação Básica.

Ainda dialogando com os professores acerca da formação dos mesmos em relação ao ensino da FMC, sobretudo com o intuito de identificarmos, em seus discursos, as marcas das posturas dos docentes formadores de professores com os quais haviam trabalhado, seguem outras constatações. Reportando-se às aulas de Mecânica Quântica, o professor $\mathrm{P}_{2}$ menciona:

"As aulas eram expositivas. É... sempre expositivas. O quadro era usado em excesso. Assim, muitas equações, muitas definições. É, a gente sente também a questão da explicação. Por mais que o professor saiba, mas, há a dificuldade em transmitir aquele conbecimento. [...] São conceitos totalmente abstratos. Não é uma coisa que você visualiza. Faz parte do micro.... E uma coisa totalmente abstrata, certo? [...] Como que ele poderia demonstrar o comportamento da particula através do spin [...] $A$ disciplina se resumia nisso". ( $\left.\mathrm{P}_{2}\right)$

Percebe-se, no discurso do professor $\mathrm{P}_{2}$, que nas aulas de Mecânica Quântica priorizava-se a apresentação do formalismo matemático, em detrimento das considerações epistemológicas e ontológicas subjacentes ao objeto do conhecimento. Este formalismo, conforme mencionado anteriormente, parece-nos ter se tornado a percepção predominante dos professores $\mathrm{P}_{1}$ e $\mathrm{P}_{2}$ em relação à FMC. Ainda em relação às abordagens utilizadas nas aulas de 
Monteiro, M. A.; Nardi, R.; Bastos Filhos, J. B.

Mecânica Quântica, também não percebemos qualquer preocupação com o sujeito do conhecimento, contrapondo assim a concepção freireana de que ensinar não é transferir conhecimento, mas criar possibilidades à construção do mesmo pelos envolvidos nas interações de ensino e aprendizagem (FREIRE, 2006).

Ampliando as evidências de que as aulas da Mecânica Quântica pautavam-se na transmissão do conhecimento, faremos recortes na fala do professor $\mathrm{P}_{2}$ acerca das respectivas avaliações de aprendizagem.

\begin{abstract}
"Basicamente, as listas de exercícios e as provas ao final de cada unidade. [...] Se não fossem as listas, não dava pra faz̧er as provas. [...] É que as questões da prova eram semelhantes às das listas; às vezes, até bem mais fáceis. Só que a gente tinha uma semana pra fazer as listas, e as provas, não". ( $\left.\mathrm{P}_{2}\right)$
\end{abstract}

Freire (2006) discute as dificuldades de um professor, que teve sua formação pautada na memorização mecânica e repetição de ideias, em tornar-se um professor crítico, tendo em vista que não percebe nenhuma relação desse conhecimento memorizado com as estruturas que necessitam ser questionadas. Esse conhecimento não ressoa com os conhecimentos sociais.

Diante deste conjunto de encaminhamentos que permearam o curso de Mecânica Quântica frequentado pelos professores entrevistados, esboçamos os seguintes questionamentos: De que lugar falavam e para quem falavam os docentes da componente curricular Mecânica Quântica, haja vista que não demonstravam o entendimento de que estavam compondo a formação de professores de Física, mas de memorizadores e reprodutores de um formalismo matemático? Onde estava o aspecto político do ensinar e do aprender?

Como poderia ter sido delineada a autonomia do professor de Física, a partir das abordagens mencionadas, para transformar e recriar o conhecimento? Percebemos, neste contexto das aulas e das avaliações de aprendizagem da Mecânica Quântica, as marcas de uma educação que Freire denomina, ao longo da sua obra, de educação bancária. Isso porque a ação permitida aos estudantes no contexto das interações em sala de aula foi a de guardar conhecimento e, posteriormente, devolvê-lo. Segundo Freire (1993), essa concepção de educação perpassa por uma dicotomia homens-mundo, e não uma relação do homem com o mundo 4 .

Pela perspectiva das abordagens nas aulas de Mecânica Quântica - repetição dos conteúdos pelo docente, seguindo a mesma sequência dos livros didáticos, exercícios de fixação e repetição dos mesmos pelos licenciandos nas avaliações - questionamos de onde vem essa voz sem nome que determina que a estrutura das aulas de física mantenha-se guiando a prática de gerações, em todos os níveis de ensino. Apesar do aparente anonimato, essas determinações têm origem, conforme menciona Orlandi (2002).

${ }^{4}$ Acerca de um viés dessa discussão, ver Bassalo (2003) e Bastos Filho (2001). 
Como um professor de Física que foi submetido ao padrão de formação acima poderá desenvolver estratégias no intuito de que, por meio da introdução da FMC no Ensino Médio, possa desencadear situações que se destinam a contribuir para uma educação científica crítica e emancipatória, tendo em vista que tal perspectiva foi relegada na formação do mesmo? Delizoicov, Angotti e Pernambuco (2002), por exemplo, criticam a repetição sistemática dos conhecimentos para os diversos níveis de escolaridade e níveis cognitivos. Os autores alegam quanto essa abordagem é prejudicial à socialização da ciência e da tecnologia.

Embora os professores $\mathrm{P}_{1}$ e $\mathrm{P}_{2}$ hajam considerado que suas formações, em termos da FMC, tenham sido bastante satisfatórias, os mesmos não se mostram com autonomia para recriarem o conhecimento, no intuito de dialogarem com os estudantes do Ensino Médio. Tendo em vista esta ausência de condições de autonomia dos professores em relação ao ensino da FMC, percebe-se que a atuação dos mesmos provavelmente se dará a partir de atitudes que se distanciam de uma educação pautada no agir comunicativo, haja vista que a própria formação dos mesmos distanciou-se desta perspectiva.

Conforme pontua Carr (1996), em uma perspectiva educacional pautada no agir comunicativo, um dos principais objetivos é propiciar a autonomia racional aos educadores, no intuito de, coletivamente construírem sua compreensão de mundo e, sobretudo, as suas práticas pedagógicas. Segundo Mühl (2003a), uma prática pedagógica participativa emerge da práxis comunicativa, tendo em vista que tal prática não mais é um agir instrumental, tornando-se um processo cooperativo entre os envolvidos na construção do conhecimento. Neste sentido, uma prática escolar que se fundamenta em uma perspectiva habermasiana deverá estar articulada com o mundo da vida.

Sobre a potencialidade da ação comunicativa na formação dos professores, Mühl assinala:

O que caracteriza uma educação crítico-comunicativa é sua preocupação com a emancipação dos professores de suas crenças irracionais e de suas idéias unilaterais herdadas das patologias provenientes de uma comunicação sistematicamente distorcida, que se manifesta no seu mundo de vida, bem como das ideologias predominantes em seu contexto social [...]. (MÜHL, 2003b, p. 321)

Vale aqui salientar que o professor que, em qualquer nível de ensino, optar por arriscar-se por meio das teorizações do agir comunicativo, certamente encontrará uma série de obstáculos, tais como: currículos, a estrutura administrativa das instituições escolares, a opção de outros por determinadas práticas e metodologias e, até mesmo, pela ausência de relações entre as componentes curriculares.

No contexto da formação de professores, entendemos que a ação dialógica freireana faz aliança com a proposição da ação comunicativa habermasiana e, certamente, ambas apresentam-se como referenciais autênticos para superação da racionalidade instrumental nas esferas educacionais, haja vista que ambas as teorizações primam pela emancipação do sujeito na sociedade, a partir das interações entre os sujeitos, interações estas que, atualmente, estão bastante ofuscadas pela dominação ensejada pelos interesses do capital. 
Monteiro, M. A.; Nardi, R.; Bastos Filhos, J. B.

Habermas (1990) parte da intersubjetividade da linguagem com a finalidade do entendimento entre os sujeitos, assumindo papel relevante na emancipação. Ainda na esteira desta postura, o conceito habermasiano de verdade torna-se igualmente fértil, tendo em vista que esta não é uma adequação da verdade à realidade, mas a verdade a partir do consenso entre os sujeitos falantes - consenso que emerge a partir do diálogo visando o entendimento.

Tanto para Freire quanto para Habermas, o diálogo só poderá existir a partir do reconhecimento e do respeito pelas diferenças. É neste reconhecimento que se encontram a fecundidade da ação dialógica e da ação comunicativa no contexto educacional. Se em Freire a educação bancária subverte a capacidade reflexiva dos sujeitos, em Habermas impede a capacidade de sair dos processos comunicativos cotidianos para o agir comunicativo. Destaca-se aqui que, apesar de Freire e Habermans partirem de pressuposições distintas, há essa convergência no tocante ao diálogo, enquanto construção da autonomia.

\section{Considerações finais}

Apesar do crescente número de pesquisas, com justificativas diversas, advogando a introdução da FMC no Ensino Médio, conforme constatam Ostermann e Moreira (2000), Greca e Moreira (2001) e Monteiro e Nardi (2007), não se observa tal entusiasmo entre os professores de física que fazem parte da presente pesquisa. Ao contrário, percebe-se, nos discursos dos mesmos, as marcas de uma formação profissional pautada em perspectivas teóricas que os inviabilizam em tal empreitada; em particular, há uma formação pautada na racionalidade técnica, especialmente no tocante à separação entre "disciplinas pedagógicas" e "disciplinas de conteúdos específicos", inviabilizando uma compreensão minimamente satisfatória do próprio objeto do conhecimento pelos professores.

Conforme o perfil de formação de professores mencionado acima, está distante dos professores planificarem estratégias de ensino contemplando a FMC, com o intuito de possibilitarem, aos estudantes do nível médio, a construção de uma visão cultural da ciência, conforme sugestões de Torre (1998), ou, mesmo, a física articulada com a cultura (CARVALHO e ZANETIC, 2004), com questões sociais mais amplas (ZANETIC, 2005) ou uma visão mais coerente da Física, bem como da natureza do trabalho científico, tal qual sugerem Gil Pérez, Senet e Solbes (1987). Entendemos que, para a FMC ser introduzida no Nível médio da Educação Básica, é imprescindível se discutirem, urgentemente, outras perspectivas para a formação de professores de Física.

Seria pertinente que aqueles que defendem, a todo custo, a introdução da FMC na Educação Básica, no intuito de "modernizarem" os currículos, refletissem sobre as suas intenções. Acerca desta questão, as palavras do Lévy-Leblond certamente ajudam a ampliar o debate. O mesmo assinala:

Assim, em vez de querer modernizar a todo custo os conteúdos específicos do ensino científico, parece-me muito mais urgente levar os alunos à compreensão do que é realmente Ciência, de seus processos de trabalho, seus desafios epistemológicos, suas implicações sociais. (LÉVY-LEBLOND, 2002, p. 72, grifos nossos) 
A sistemática incompreensão da teoria...

\section{Referências}

ADORNO, T.; HORKHEIMER, M. Dialética do esclarecimento: fragmentos filosóficos. Rio de Janeiro: Zahar, 1985.

ALMEIDA, M. J. P. M. Meio século de Educação em Ciências: uma leitura de recomendações ao professor de física. 2003. 111f. Tese (Livre Docência em Metodologia de Ensino: Física) - Faculdade de Educação, Universidade de Campinas, Campinas, 2003.

ARONS, A. B. A guide to introductory physics teaching. New York: John Wiley, 1990.

AUBRECHT, G. J. Report on the conference on the teaching of modern physics. The Physics Teacher, Boone, v. 24, n. 9, p. 540-546, 1986.

BAKHTIN, M. Marxismo e filosofia da linguagem. São Paulo: Hucitec, 2006.

BASSALO, J. M. F. Ensino: "bancário" ou holístico, 2003. Disponível em: <http:// www.bassalo.com.br/mm_magensino.asp>. Acesso em: 4 jan. 2009.

BASTOS FILHO, J. B. Dangerous effects of the incomprehensibility in microphysics. In: BARONE, M.; SELLERI, F. (Orgs.). Frontiers of fundamental physics. New York: Plenum Press, 1994. p. 485-492.

A ciência normal e a educação são tendências opostas?, In: BURSZTYN, M.

(Org.). Ciência, ética e sustentabilidade. São Paulo: Cortez, 2001. p. 61-94. Disponível em: <http://unesdoc.unesco.org/images/0012/001274/127492por.pdf>. Acesso em: 4 nov. 2008.

O ensino da mecânica quântica e o paradoxo da compreensão. In: ENCONTRO DE PESQUISA EM ENSINO DE FÍSICA, 9., 2004, Jaboticatubas. Anais... São Paulo: SBF, 2004. 1 cd-rom.

BOHR, N. Discussion with Einstein on epistemological problems in atomic physics 1949'. Disponível em: <http://minerva.tau.ac.il/bsc/3/3144/bohr.pdf>. Acesso em: 30 mai 2009.

BRASIL. Ministério da Educação e do Desporto. Secretaria de Educação Fundamental.

Parâmetros curriculares nacionais + ciências da natureza, matemática e suas tecnologias - física. 4. ed. Brasília: SEF, 2002.

CARR, W. Una teoria para la educación. Madrid: Morata, 1996.

CARVALHO, S. H. M.; ZANETIC, J. Ciência e arte, razão e imaginação: complementos necessários à compreensão da física moderna. In: ENCONTRO DE PESQUISA EM ENSINO DE FÍSICA, 9., 2004, Jaboticatubas. Anais... São Paulo: SBF, 2004. 1 cd-rom.

DELIZOICOV, D.; ANGOTTI, J. A.; PERNAMBUCO, M. M. Ensino de ciências: fundamentos e métodos. São Paulo: Cortez, 2002.

FEYNMAN, R. P.; LEIGHTON, R.; SANDS, M. Lectures on Physics. Massachusetts: Reading, 1965. v. 3. 
Monteiro, M. A.; Nardi, R.; Bastos Filhos, J. B.

FOUCAULT, M. A arqueologia do saber. 7. ed. Rio de Janeiro: Forense Universitária, 2005.

FREIRE, P. Pedagogia do oprimido. Rio de Janeiro: Paz e Terra, 1993.

Pedagogia da autonomia. Rio de Janeiro: Paz e Terra, 2006.

GASKELL, G. Entrevistas individuais e grupais. In: BAUER, M. W.; GASKELL, G.

(Orgs.). Pesquisa qualitativa com texto, imagem e som: um manual prático. 2. ed.

Petrópolis: Vozes, 2003. p. 244-270.

GIL PEREZ, D.; SENET; F.; SOLBES, J. La introduccion a la física moderna: un ejemplo paradigmatico de cambio conceptual. Enseñanza de las Ciencias, Barcelona, n. extra, p. 189-195, 1987.

.; SOLBES, J. The introduction of modern physics: overcoming a deformed vision

of science. International Journal of Science Education, London, v. 15, n. 3, p. 255-260, 1993.

GRECA, I. M.; MOREIRA, M. A. Uma revisão da literatura sobre estudos relativos ao ensino da mecânica introdutória. Investigações em Ensino de Ciências, Porto Alegre, v. 6, n. 1, p. 29-56, 2001.

HABERMANS, J. Teoría de la acción comunicativa: crítica de la razón funcionalista. Madrid: Taurus, 1987. (Tomos I e II).

. Pensamento pós-metafísico. Rio de Janeiro: Tempo Brasileiro, 1990.

Ciência e técnica enquanto ideologia. Lisboa: Edições 70, 2006.

ISCHLER, H.; LICHTFELDT, M. Modern physics and students' conceptions.

International Journal of Science Education, London, v. 14, n. 2, p. 181-190, 1993.

LÉVY-LEBLOND, J. M. É possível ensinar a física moderna na educação básica? In: MORIN, E. (Org.). A religação dos saberes: o desafio do século XXI. Rio de Janeiro: Bertrand Brasil, 2002. p. 69-72.

MACHADO, D. I.; NARDI, R. Avaliação do ensino da física moderna e contemporânea no Ensino Médio. In: ENCONTRO NACIONAL DE PESQUISADORES EM EDUCAÇÃO EM CIÊNCIAS, 4., 2003, Bauru. Anais... Bauru: ABRAPEC, 2003. 1 cd-rom.

MONTEIRO, M. A.; NARDI, R. Tendências das pesquisas sobre o ensino da física moderna e contemporânea apresentadas nos ENPEC. In: ENCONTRO NACIONAL DE PESQUISA EM EDUCAÇÃO EM CIÊNCIAS, 6., 2007, Florianópolis. Anais... Belo Horizonte: ABRAPEC, 2007. 1 cd-rom.

MÜHL, E. H. Habermans: ação pedagógica como agir comunicativo. Passo Fundo: UPF, 2003a.

Educação e emancipação: construção e validação consensual do conhecimento pedagógico. In: MÜHL, E. H.; FAVERO, A. A.; DALBOSCO, C. A. (Orgs.). Filosofia, educação e sociedade. Passo Fundo: Editora UPF, 2003b. p. 61-72. 
A sistemática incompreensão da teoria...

OLIVEIRA, F. F.; VIANNA D. M.; GERBASSI, R. S. Física moderna no Ensino Médio: o que dizem os professores. Revista Brasileira de Ensino de Física, São Paulo, v. 29, n. 3, p. 447-454, 2007.

ORLANDI, E. P. A linguagem e seu funcionamento. 2. ed. Campinas: Pontes, 1987.

As formas do silêncio: no movimento dos sentidos. Campinas: Editora da Unicamp, 1995.

Discurso e texto: formulação e circulação dos sentidos. Campinas: Pontes, 2001.

Análise de discurso. 4. ed. Campinas: Pontes, 2002.

Autoria, leitura e efeitos do trabalho simbólico. Campinas: Pontes, 2004.

Discurso e leitura. São Paulo: Cortez, 2006.

OSTERMANN, F; MOREIRA, M. A. Uma revisão bibliográfica sobre a área de pesquisa "física moderna e contemporânea" no Ensino Médio. Investigações em Ensino de Ciências, Porto Alegre, v. 5, n.2, paginação eletrônica, 2000.

PÊCHEUX, M. A análise automática do discurso. In: GADET, F.; HAK, T. (Orgs.). Por uma análise automática do discurso: uma introdução a obra de Michael Pêcheux. Campinas: Editora da Unicamp, 1983. p. 61-105.

O discurso: estrutura ou acontecimento. 4. ed. Campinas: Pontes Editores, 2006.

PEREIRA, J. D. Formação de professores: pesquisas, representações e poder. Belo Horizonte: Autêntica, 2000.

SHABAJEE, P.; POSTLETHWAITE, K. What happened to modern physics? School Science Review, Hertfordshire, UK, v. 81, n. 297, p. 51-56, 2000.

SILVA, T. T. Documentos de identidade: uma introdução às teorias do currículo. 2. ed. Belo Horizonte: Autêntica, 2004.

SILVA, T. T.; MOREIRA, A. F. B. Sociologia e teoria crítica do currículo: uma introdução. In:__. Currículo, cultura e sociedade. 6. ed. São Paulo: Cortez, 1994. p. 7-37.

SOLBES, J.; FERNÁNDEZ, P.; GONZÁLEZ, E. Carencias en la formación docente en temas de física contemporánea en Argentina. In: CONGRESO INTERNACIONAL DE INVESTIGACIONES EN ENSEÑANZA DE LAS CIENCIAS, 1., 2001, Barcelona. Actas... Barcelona, 2001. 1 cd-rom.

STANNARD, R. Modern physics for the young. Physics Education, Bristol, v. 25, n. 3, p. 133-143, 1990.

TAYLOR, J. F.; ZAFIRATOS, C. Modern physics for scientist and engineers. New Jersey: Prentice-Hall, 1991.

TERRAZZAN, E. A. Perspectivas para a inserção da física moderna na escola média. 1994. 241f. Tese (Doutorado em Educação) - Faculdade de Educação, Universidade de São Paulo, São Paulo, 1994. 
Monteiro, M. A.; Nardi, R.; Bastos Filhos, J. B.

TORRE, A. C. Reflexiones sobre la enseñanza de la física moderna. Educacion en Ciências, New Jersey, v. 2, n. 4, p. 70-71, 1998.

ZANETIC, J. Física e arte: uma ponte entre duas culturas. In: ENCONTRO DE PESQUISA EM ENSINO DE FÍSICA, 8., 2002, Águas de Lindóia. Anais... São Paulo: SBF, 2002. 1 cd-rom.

. Física e cultura. Ciência e Cultura, Campinas, v. 57, n. 3, p. 21-24, 2005.

Artigo recebido em junho de 2009 e aceito em agosto de 2009. 